\title{
¿AUTÉNTICA PERUANIDAD? TRANSFORMACIONES DEL CONCEPTO DE REPRESENTACIÓN POLÍTICA EN EL PERÚ DE FUJIMORI
}

\author{
Eduardo González Cueva *
}

\section{INTRODUCCIÓN}

Este trabajo parte de una constatación que es aún difícil de aceptar para las élites políticas peruanas, a pesar de que existe creciente evidencia para sustentarla: la emergencia de argumentos nacionalistas y racistas en el actual debate sobre la crítica situación de las instituciones democráticas en el Perú actual.

Se ha hecho común durante los años del gobierno de Fujimori que los intercambios argumentales sobre la democracia se conviertan, en algún punto, en ataques más o menos explícitos acerca de la "peruanidad" de los distintos actores políticos. En 1990, el ataque chauvinista de sectores del FREDEMO al entonces candidato Fujimori por su ascendencia japonesa y su cercanía a las iglesias protestantes fue repudiado por la opinión pública y la mayoría de la prensa. Del mismo modo, el intento del candidato Fujimori de posesionarse del voto de los "chinitos y cholitos" contra los "blanquitos", fue duramente criticado'.

A mediados del segundo gobierno de Fujimori, sin embargo, asistimos a una situación distinta: los argumentos que exaltan o niegan la "auténtica peruanidad" de fujimoristas o miembros de la oposición, se han hecho comunes, aunque no se reconozcan públicamente como racistas o chauvinistas. El intercambio de acusaciones acerca de la nacionalidad del empresario televisivo Baruch Ivcher a mediados de 1997, que este trabajo presentará, nos provee de un extraordinario repertorio argumental para analizar las conexiones entre imágenes de la nación, racismo e imágenes de la democracia.

A la pregunta "¿Por qué la esfera pública peruana liga en una misma estructura argumental discursos sobre la democracia y discursos sobre la nación?", este trabajo propone como respuesta que ambos discursos se basan en un mismo supuesto: la idea de una crisis de los mecanismos e instrumentos de representación política.

El fujimorismo ha argumentado convincentemente que los antiguos mecanismos liberales de representación no solamente han fracasado funcionalmente -en tanto voceros de intereses- sino además culturalmente, en tanto imagen de la diversidad nacional. La nueva representación que ha propuesto el régimen a través de su partido y su líder, se plantea el reto no sólo de redefinir el funcionamiento de las instituciones políticas en la forma de una "nueva democracia": se ha propuesto además reconstruir la imagen de la nación.

La llamada "crisis de representación" sobre la que tanto se ha discutido en la academia y en la política peruanas ${ }^{2}$ ha ido mucho más allá de la crisis de las instancias que cumplían la función representativa, tales como los partidos y el parlamento: lo que ha cambiado en el Perú es la idea misma de lo que es representar. Hoy, "representación" se ha convertido en "representatividad": la función de defender determinados intereses se ha convertido en la función de simbolizar determinadas identidades.

A la pregunta "¿Cómo ha sido posible esta transformación en la noción de representación política?”, el trabajo plantea que éste, como todo desplazamiento semántico en nociones públicamente compartidas, debe observarse en el contexto de la particular configuración de la esfera pública en la sociedad que nos interesa. En el caso del Perú, el

Licenciado en Sociología en la Pontificia Universidad Católica del Perú. Maestro en Sociología y estudiante de Doctorado en la New School for Social Research, Nueva York. El presente artículo constituye una versión previa de un ensayo más exhaustivo a ser publicado en Perú.

Antes de iniciar el desarrollo del artículo, quisiera agradecer las múltiples observaciones y sugerencias que a ésta y a previas versiones de mi investigación han planteado mis colegas y profesores en la New School for Social Research. Agradezco en particular a Andrew Arato, Diane Davis, Oscar Espinosa de Rivero, Nancy Fraser, Martín Plot, David Plotke y Deborah Poole. También quisiera reconocer las observaciones de Romero Grompone, del Instituto de Estudios Peruanos, de Rolando Ames del Instituto Diálogo y Propuesta y de Guillermo Rochabrún, de la Pontificia Universidad Católica del Perú. Agradezco por último al Janey Program for Latin American Studies en la New School, al Instituto de Estudios Peruanos, en Lima, por poner a mi disposición los medios para desarrollar una productiva investigación de campo entre junio y agosto de 1997 en el Perú y a la Latin American Studies Association por aceptar una versión de este trabajo para su presentación en el XXI Congreso de la asociación en Setiembre de 1998 en Chicago.

1. Para un recuento testimonial de la campaña de 1990, ver Salmón (1993), Vargas Llosa (1994) y Zuzunaga (1992).

2. Ver Lynch (1992), De Soto (1993), Pease (1993), Rochabrún (1994) y Grompone (1995). 
trabajo propone a título hipotético un modelo de esfera pública, cuyas principales características son la jerarquización de distintos circuitos y modalidades de argumentación, así como el silenciamiento sistemático de áreas de la vida social que pugnan por ser tematizados, en particular la cuestión de las imágenes socialmente compartidas sobre raza, etnicidad y nación.

La esfera pública en el Perú tiene un gran "no-tema", un discurso reprimido, que aparece en formas múltiples y oblicuas en la deliberación nacional: las identidades raciales y étnicas. La vieja ideología criolla del mestizaje universal ya no basta para aplacar los deseos de inclusión de las grandes mayorías de la nación ${ }^{3}$. La construcción de la categoría incluyente de "peruanos" no puede opacar el hecho que muchas maneras de ser peruano existen y pugnan por ser reconocidas como tales.

Las transformaciones semánticas de la noción de representación política durante el régimen de Fujimori canalizaron la emergencia pública de múltiples discursos sobre el tema de las identificaciones raciales e identidades étnicas en el Perú de hoy. Los argumentos a favor de una "nueva democracia" que superase las formas "tradicionales" encarnadas en la Constitución de 1979, proponían a la vez, de manera implícita, la imagen de un nuevo régimen de jerarquizaciones raciales y étnicas, un rediseño de la nación.

A su vez, los argumentos en contra del autoritarismo fujimorista plantearon -también de manera oblicua- una forma de organización de las diferencias étnicas y raciales. No es casual que la oposición al gobierno, independientemente de reclamarse de derecha o izquierda, neoliberal o socialdemócrata, haya hecho del nacionalismo su piedra de toque: ya sea en la lucha contra los intereses extranjeros que "se apropian" de las empresas peruanas privatizadas, en el rechazo a las negociaciones con Ecuador, o en las denuncias sobre la verdadera nacionalidad de Alberto Fujimori

En la primera parte de este artículo, presentaré una propuesta de reconstrucción de una "escena deliberativa" ${ }^{4}$ : la discusión en torno a la expropiación de la cadena de televisión "Frecuencia Latina" de manos de su propietario, el empresario Baruch Ivcher. En la segunda parte, presentaré el contexto en el que aparece la discusión política sobre la "peruanidad", es decir, el modelo de la esfera pública peruana, en la que sistemas de clasificación racial e imágenes de nación son problematizados. Por último, presentaré el desarrollo específico de la discusión sobre la representación política en el régimen de Fujimori y su relación con la discusión sobre las imágenes de nación.

\section{El affaire Ivcher: ¿QQuién es peruano en el Perú?}

\section{Los hechos ${ }^{5}$}

A mediados de 1997, los espectadores de "Frecuencia Latina”, un canal de televisión que había probado en anteriores ocasiones ser un firme aliado del régimen peruano, pudieron apreciar un súbito cambio de orientación política en sus programas. El canal, que se caracterizaba por publicitar las posiciones del gobierno y que -a decir de la oposición - tenía un evidente acceso a informaciones de los servicios de inteligencia, de pronto empezó a denunciar desde su programa político "Contrapunto", uno de los más vistos del país, graves casos de corrupción y de violación de los derechos humanos.

"Frecuencia Latina" denunció a inicios de abril un horroroso caso de asesinato y tortura: el 30 de marzo de ese año, había sido hallado en las afueras de Lima el cadáver descuartizado de la agente de inteligencia Mariela Barreto. Aparentemente, Barreto había sido asesinada por miembros de su misma institución, el Servicio de Inteligencia Nacional (SIN), que la acusaban de enviar información a la prensa acerca de violaciones a los derechos humanos. Una segunda agente, Leonor La Rosa, se hallaba detenida en el Hospital Militar de Lima, donde se recuperaba de torturas que la habían dejado incapacitada.

A mediados de abril, "Frecuencia Latina" reveló que el controvertido capitán Vladimiro Montesinos, asesor presidencial a cargo de los servicios de inteligencia del régimen, ganaba cerca de un millón de dólares al año, a pesar de no tener ningún cargo oficial dentro de la estructura gubernamental.

El escándalo desatado por estos reportajes, que fueron inmediatamente ampliados y profundizados por otros medios de prensa, se sumó a la crítica situación en la que el gobierno se encontraba debido a dos crisis irresueltas: la toma de rehenes por parte del grupo guerrillero MRTA en la residencia del embajador del Japón y la sentencia del Tribuna Constitucional que declaraba inaplicable para el caso de Fujimori una ley congresal que le permitía postular por tercera vez consecutiva a la presidencia de la República en el año 2.000 .

El gobierno respondería con rapidez a sus problemas con la guerrilla, la constitución y la prensa. El 22 de abril, un comando del ejército liberó a los rehenes del MRTA en una violenta acción en la que murieron todos los miembros del grupo guerrillero; a fines de mayo, el parlamento, dominado por la bancada del partido de gobierno, destituyó a los miembros del Tribunal Constitucional que habían dictado sentencia contra la reelección; por último, entre mayo y junio el gobierno difundió versiones periodísticas que pretendían destruir la imagen del propietario de "Frecuencia Latina", el empresario israelí nacionalizado peruano Baruch Ivcher. Según estas versiones, Ivcher había roto relaciones con el gobierno debido a que no había obtenido una serie de contratos de gran importancia económica; adicionalmente -se insinuaba- Ivcher mantenía contactos con el ejército del Ecuador, país con el que el Perú ha mantenido una larga disputa fronteriza.

A las acusaciones se sumarían amenazas, investigaciones de las autoridades fiscales y una peligrosa maniobra: a mediados de julio, el ministro del interior declaró a la prensa que los documentos por los cuales Ivcher había obtenido la nacionalidad peruana hacía trece años "no existían físicamente", por lo que el proceso de naturalización del

3. Este es el argumento de Franco (1993)

4. Debo esta noción a Martín Plot (1998).

5. Para la reconstrucción de los hechos descritos en esta sección me apoyo en fuentes directas: reportes del diario La República, la revista Caretas, grabaciones de programas televisivos de "Frecuencia Latina" y de la cadena "Uranio 15" a lo largo de 1997. 
empresario estaba viciado y podía ser declarado nulo. Esta maniobra tenía graves consecuencias legales: de acuerdo a la ley peruana, ningún extranjero puede poseer empresas de comunicación masiva, que es la razón por la cual Ivcher se había nacionalizado peruano. La anulación de la propiedad de Ivcher sobre su empresa tendría el resultado de transferir el control de la cadena a los socios minoritarios, los hermanos Samuel y Mendel Winter, personas de confianza del régimen.

Los ataques del gobierno fueron respondidos por "Frecuencia Latina" con la denuncia de un nuevo escándalo. Al día siguiente de la denuncia del ministro del interior, el programa "Contrapunto" difundió grabaciones de escuchas telefónicas que los servicios de inteligencia habían realizado ilegalmente contra un centenar de políticos de oposición, empresarios y hasta celebridades del espectáculo.

A esta declaración de guerra, el gobierno respondió con la anulación de la nacionalidad peruana de Ivcher. Una resolución firmada por un funcionario militar del ministerio del Interior -el coronel Víctor Huamán- dejaba sin efecto el título de nacionalidad peruana debido a vicios de procedimiento. La acción provocó general indignación y manifestaciones de solidaridad de los televidentes, que hicieron miles de llamadas a "Frecuencia Latina" y -en varias ocasiones- tomaron las calles aledañas a la estación para bloquear un rumoreado intento policial de desalojar a los periodistas y a la administración leal a Ivcher.

A la defensa de la peruanidad legal de Ivcher se sumó inmediatamente un ataque a la propia ciudadanía de Fujimori, merced a una investigación periodística que arrojaba dudas sobre el verdadero lugar de nacimiento del presidente. Fujimori, quien supuestamente habría nacido en el Perú el 28 de julio (día de la independencia nacional) de 1938, habría nacido en realidad en el Japón. Documentos del archivo nacional estudiados por una periodista aparentemente demostraban que la madre del presidente había entrado por primera vez al país en 1934 con dos niños pequeños, uno de los cuales sería Alberto Fujimori.

La autora de la investigación, Cecilia Valenzuela, mostró en el programa televisivo del periodista César Hildebrandt la partida de nacimiento del presidente, que mostraba claras señales de haber sido adulterada y que señalaba como lugar de nacimiento una localidad inexistente llamada "Carrera de Surco". La partida de bautismo del presidente también mostraba señales de adulteración. Esta denuncia tuvo el efecto de una bomba: de acuerdo a la constitución peruana, es requisito indispensable para ejercer la presidencia de la república el haber nacido en el país: si Fujimori era, en efecto, extranjero de nacimiento, su presidencia sería ilegal.

Adicionalmente, la prensa descubrió un nuevo hecho paradójico: los hermanos Samuel y Mendel Winter-accionistas minoritarios de "Frecuencia Latina", favorecidos por la anulación de la nacionalidad de Ivcher- usaban pasaportes polacos en sus viajes al extranjero. ¿Cómo podía acusarse a Ivcher de no ser peruano y, a la vez, entregar su empresa a dos personas que tampoco lo eran?

En defensa del presidente se presentaron distintos argumentos que cuestionaban la validez de la investigación periodística y trataban de explicar las supuestas adulteraciones e incongruencias de los documentos. Uno de los argumentos utilizados para explicar la mención a un lugar inexistente en la partida de nacimiento eran los problemas lingüísticos de los padres de Fujimori: si el funcionario público había consignado como lugar de nacimiento, la "Carrera de Surco" esto se debía a que los inmigrantes japoneses habían pronunciado erróneamente el nombre de un lugar real: la Calera de Surco. La defensa presidencial fue vigorosamente contraatacada por la prensa opositora; el periodista Hildebrandt consideraba el argumento lingüístico absurdo: uno de los testigos que figuraba en el acta de nacimiento se apellidaba Quispe (un apellido quechua). ¿cómo así podía explicarse que alguien con tan "peruanísimo apellido" no corrigiese el error del funcionario?

La disputa de las nacionalidades se llevó a las calles: en masivas manifestaciones de apoyo a "Frecuencia Latina" la multitud coreaba las consignas "¡Ivcher es peruano!" y “¡Fujimori no es peruano!”. La programación del canal se volvió una permanente guerrilla televisiva, con discusiones políticas a toda hora y video-clips que repetían hasta el cansancio el jingle "Un canal que nunca dejará de ser peruano”. En una de las manifestaciones, la congresista opositora Lourdes Flores, atacó al coronel Huamán, responsable de la anulación de la nacionalidad de Ivcher cuestionando su capacidad intelectual con la frase “iQué tal huamán!” que, en el argot criollo -que asocia los apellidos indígenas a la estupidez- equivale a un insulto. Las acusaciones de racismo no se hicieron esperar y la congresista se apresuró a hacer una disculpa pública por el uso de la frase.

\section{Muchos apellidos, muchas peruanidades}

El dramatis personae de esta historia tiene nombres como Ivcher, Fujimori, Winter, Hildebrandt, Flores, Huamán. ¿Cuál de estos apellidos podría considerarse "peruano" en una disputa desligada del contexto político que hemos examinado? Presumiblemente, tanto Ivcher como Fujimori delatan un origen que no es ni español ni indígena. Huamán o Quispe, por otro lado, pueden ser considerados "peruanísimos" sólo en un sistema de clasificaciones que identifique "lo peruano" con lo típico o lo primigenio y esto, a su vez, con "lo indígena”.

En el enrarecido contexto de la política peruana en 1997, sin embargo, la pregunta por la autenticidad nacional de uno u otro actor evocaba dos dimensiones paralelas: por un lado, una reflexión sobre la relación entre identidad nacional e identidades étnicas; por otro lado, una decisión estratégica, en la que reclamar "peruanidad" equivalía a reclamar la franquicia necesaria para participar en el juego político.

En ambos niveles, el cultural y el político, se trataba de hallar una solución al problema de la pluralidad nacional. En el primer nivel, se problematizaba públicamente -aunque de manera oblicua- un tema que usualmente permanece oculto en la sociedad peruana: los sistemas de clasificación racial y étnica. Los presupuestos del discurso clasificatorio, que usualmente permanecen ocultos, emergían aquí y allá en forma de síntomas. 
En el segundo nivel el problema era el de cómo relacionar la pluralidad con la participación y la inclusión: si Ivcher no era peruano -en el sentido de poseer un título de ciudadanía válido- dejaba de ser un actor político, y lo mismo pasaba con Fujimori. De lo que se trataba en este nivel era de establecer el alcance de la inclusividad del espacio político a través del establecimiento de la dicotomía amigo-enemigo: "...definiciones que operan con la distinción entre verdadero y falso, auténtico y apócrifo [son] reflejos de distinciones genuinamente políticas, y su "verdadero" o "falso", "auténtico" o "apócrifo" es el reflejo de una distinción concreta entre correligionarios y enemigos." (Schmitt 1995, 61).

Pero la forma de la discusión no se expresaba en términos de quién era ciudadano, sino de quién era peruano: por esto era posible escuchar a uno de los manifestantes que apoyaba a Ivcher quejarse amargamente de que el país estuviera dominado "por una persona que ni siquiera tiene sangre peruana en las venas". Las formas de clasificación étnica y racial, marcadas por nociones esencialistas de herencia y del derecho de sangre se superponían a las formas de clasificación jurídicas, marcadas por el derecho de suelo.

Esta no era una situación nueva en la política peruana: ya en 1990 y en 1995 se había podido apreciar la superposición de ambos niveles a través del uso de códigos ambiguos que aludían al mismo tiempo a "esencias" raciales o etnicas y a la condición ciudadana legal. En 1990, en el contexto del enfrentamiento electoral entre el escritor Mario Vargas Llosa y el virtualmente desconocido ingeniero Fujimori, los seguidores del escritor cuestionaron también la peruanidad del entonces candidato: algunos utilizaron la estrategia legal de determinar si había realmente nacido en el Perú, otros -sin necesidad de responder a esta pregunta- le acusaban de no encarnar adecuadamente las características esenciales de una supuesta peruanidad: el "no tener ancestros enterrados en el país", el postular a la presidencia con el apoyo de religiosos evangélicos en un país tradicionalmente católico, etc.

En 1995, la oposición cometió el mismo error que en 1990: puso al frente de Fujimori a otro notable, el ex-secretario general de las Naciones Unidas Javier Pérez de Cuéllar, con los mismos argumentos con los que se había publicitado a Vargas Llosa, como prestigio internacional y excelente formación profesional. Pérez de Cuellar, como el escritor, era un "candidato de lujo", una persona "decente”, palabras código que significan que la persona de quien se habla es socialmente considerada "blanca". La candidatura del ex-secretario general no hizo más que perder fuerza durante toda la campaña electoral y terminó desastrosamente; pero no sin sobresaltos para el presidente: un nuevo outsider, el economista Alejandro Toledo tuvo un fugaz momento de rápido crecimiento en las encuestas.

Toledo -una persona de clara ascendencia indígenahizo su campaña con la clara intención de hacer una reflexión sobre la identidad nacional y la discriminación racial. En ese camino, encontró un escenario de dramática polarización: "...habíamos tocado una fibra muy sensitiva, que era el tema de la identidad (...) ¿era cierta afinidad de nuestra piel? ¿de nuestras caras? ¿era por contraposición a Fujimori? Hay algo latente que se prendió, tocamos una fibra muy sensitiva a flor de piel..." (Toledo, 1997). En ciertos públicos, el mismo apellido del candidato fue cariñosamente transformado en "Choledo", para establecer una relación entre el nombre del primer gran virrey del Perú y la palabra cholo, con la que el lenguaje diario se refiere a las personas de ascendencia indígena. Sus slogans "el cholo de oro" y "el candidato con el color de tu tierra" fueron vigorosamente contraatacados por la prensa cercana al régimen que le acusaron de fomentar una "guerra racial" en el Perú.

La recurrente dicotomización peruano - no peruano debe ser analizada en el contexto de los dos ámbitos en los que se recrea y cuyos presupuestos confunde en un discurso ambiguo ${ }^{6}$. El primero es el marco temático general de la esfera pública peruana; el segundo, el marco temático particular de la esfera política.

\section{Un modelo para entender la esfera pública en el Perú}

Comprender las ambigüedades y eclecticismos de los discursos sobre la identidad nacional, la raza o la representación política requiere conocer el espacio de interacción argumentativa donde estos conceptos hallan su significado ${ }^{7}$ La esfera pública es el conjunto donde se articulan, con diferentes grados de institucionalización, distintos niveles de intercambio argumentativo: en ella, ciertos participantes y temas reciben atención privilegiada y constituyen paradigmas de normalidad, mientras otros reciben varias formas de exclusión y pugnan por ganar reconocimiento a través de circuitos alternativos de discusión o madalidades discursivas distintas.

Los temas y actores excluídos suelen ganar una súbita relevancia, ya sea en sus propios términos o a través de discusiones aparentemente distintos. Este es el caso de las formas de clasificación e identificación racial y étnica en el Perú, que constituyen el gran "no-tema" de la esfera pública, negados de todo examen crítico y cubiertos bajo un velo superficial -el rechazo nominal del racismo- y otro viejo y rasgado: la ideología criolla que sostiene que el Perú es una nación homogéneamente mestiza. Este es el problema que emerge en la escena deliberativa que examinamos líneas arriba a través de discursos que -aparentemente- se refieren a problemas específicos de la transición democrática, tales como la autonomía de la prensa, el equilibrio de poderes, el control civil sobre los militares, etc.

La esfera pública peruana, donde esta súbita emergencia de temas excluidos es posible, es muy peculiar. No se asemeja al modelo clásico de la esfera pública burguesa que Habermas (1962) intentó sintetizar; un ámbito público

6. Esta, por cierto, no es la única opción posible. Psicoanalistas como Delgado Díaz del Olmo (1992) y Hernández (1993) sugieren una exploración de los traumas fundacionales de la sociedad peruana y de la condición mestiza.

7. En esta sección me apoyo en una lectura crítica de Habermas (1962) y Fraser (1992). El modelo de esfera pública que construyo debe mucho al curso "Rethinking the Public Sphere" dictado por Nancy Fraser en la New School for Social Research en el otoño de 1996. 
homogéneo, abierto a la participación de individuos iguales en la identidad universal de la ciudadanía, donde la argumentación escrita es el modo discursivo privilegiado. Por el contrario, la esfera pública de la que hablamos se caracteriza por su pluralidad estructural, las ambiguas relaciones de subordinación o competencia entre sus distintos circuitos, los diversos grados de apertura a temas diversos y la diversidad de prácticas comunicativas.

En efecto, mientras el modelo clásico supone un largo proceso de formación de un público burgués cultivado que se integra a la ciudadanía, la realidad histórica peruana ha dejado muy poco espacio para la constitución de la población en un público de ciudadanos ${ }^{8}$. Los temas que se discuten en el ámbito público no necesariamente cumplen una función integradora, porque no todos participan en las mismas condiciones y porque los temas no necesariamente emergen de procesos públicos de tematización, sino a propuesta de las instancias de poder que controlan la discusión mediante de un acceso privilegiado a los medios masivos y mediante la formación de públicos-clientela.

La esfera pública oficial, constituída por las instancias estatales sujetas a deliberación como el parlamento y las cortes de justicia, es un ámbito reducido y desconectado de otros públicos alternativos. En los países capitalistas avanzados, con estructuras estatales que penetran toda la sociedad, este nivel oficial de la esfera pública es considerada un "público fuerte" por su capacidad de dar relevancia a los aspectos que tematiza y de producir decisiones consecuenciales para todos los miembros de la comunidad (Fraser, 1992). Esta imagen, sin embargo, no es necesariamente la más adecuada para describir la posición de las instituciones parlamentarias o de la magistratura en el Perú, un país de instituciones débiles, cuyas discusiones son vistas como meras formalidades por los participantes en una miríada de públicos alternativos.

Pueden distinguirse en el Perú: (a) un público oficial formado por las débiles instituciones democráticas deliberativas; (b) un público no oficial pero integrado, formado por los medios de comunicación masiva, las asociaciones de la sociedad civil no popular y por la "intelectualidad", una élite no especializada que oscila entre las instituciones educativas, la prensa y las funciones políticas, y (c) un público liminal formado por los movimientos de la sociedad civil popular, cuyo acceso al debate nacional se da desde los márgenes y que debe pugnar constantemente por reconocimiento. Es importante notar que esta distinción de niveles no es necesariamente comprensiva, pues existen sectores desligados de lo público "por arriba y por abajo" de la estructura: desde arriba, las instancias ejecutivas del poder burocrático y empresarial no sometido a debate; desde abajo, aquellos sectores populares no organizados, la atomizada masa de la pobreza extrema.

El espacio liminal, que se ha desarrollado a partir del explosivo crecimiento de la "plebe urbana” (Franco, 1991) en el presente siglo, tiene ambiguas relaciones con el poder y el público oficial. A veces ha jugado el rol de correa de transmisión para integrar en el sistema político a sectores sociales hasta entonces excluídos a través de la expansión de la ciudadanía o de estrategias clientelistas, otras veces, ha constituído frentes confrontacionales donde se ha alimentado una cultura popular alternativa. La recurrencia de estilos de liderazgo populista en el Perú es un resultado directo de la reproducción de una esfera pública fracturada y estratificada.

La noción de peruanidad juega un rol crítico en esta situación, puesto que es uno de los pocos conceptos que propone una imagen de unidad entre los diversos estamentos de lo público. La peruanidad se construye más fácilmente por negación que por afirmación, de hecho la historia política nacional está plagada de discursos que construyen imágenes de otredad cultural, moral o legal de acuerdo a las orientaciones ideológicas en boga: el indio, la subversión, los países vecinos, el imperialismo, etc. En la ausencia de una noción inclusiva de ciudadanía que nos haga vernos como iguales, tendemos a imaginar nuestra deseada homogeneidad rechazando los peligros externos y el pluralismo interno".

El rechazo del pluralismo interno no quiere decir que no existan sistemas de clasificación que ayudan a reconocer estratificaciones sociales, identidades étnicas, y a establecer identificaciones raciales: esos sistemas existen pero no se problematizan públicamente. Se utilizan y habla de ellos a media voz en los circuitos de la vida doméstica, en la intimidad de los temas dolorosos ${ }^{10}$.

La represión del tema de nuestra capacidad de identificar a los otros (y a uno mismo) racialmente es dolorosa porque es una forma de clasificación que entraña formas de discriminación y desprecio. Por esa razón los peruanos tienden a aceptar la existencia del racismo como un problema en su sociedad, pero niegan el ser individualmente racistas, produciendo así una aceptación ambigua, un "sí pero no" que convierte al racismo en una abstracción que no puede ser aprehendida directamente.

El discurso negador del racismo va de la mano de una ideología criolla que proyecta la imagen de una nación donde el mestizaje ha producido una tal heterogeneidad que hace inútil el tratar de establecer clasificaciones, es decir una heterogeneidad tan extrema que produce el mismo efecto que la homogeneidad más radical. Esta ideología ha tenido una utilización política tranquilizadora que evitaba la problematización de temas potencialmente peligrosos y facilitaba la identificación de los públicos populares con élites políticas de procedencia oligárquica que de otro modo hubieran quedado en evidencia como distintas de los sectores que aspiraban a representar. La historia política de los años 90 en el Perú muestra, sin embargot la fase final de la descomposición de una ideología que se ha derrumbado junto con el viejo sistema oligárquico de contención de las masas campesinas indígenas

8. Pueden hallarse indicadores de integración relativa de la población a los beneficios de la condición ciudadana en López (1997).

9. Carlos Iván Degregori (1991) enfatiza el aspecto positivo de la discusión pública sobre la peruanidad. Sostiene que existe una vertiente en la cultura popular que busca imaginar la condición de ser peruanos al interior de la categoría universalista de ciudadanía.

10. La dimensión subjetiva del problema del racismo en el Perú ha sido analizada por Callirgos (1993). 
y que ha permitido la emergencia súbita y discontinua del tema racial en el escenario político (Franco, 1993).

La tematización de las identificaciones raciales se hace aún más difícil porque la estructuración del ámbito público en una pluralidad de niveles más o menos permeables permite hasta cierto punto que actores hábiles puedan tomar la decisión estratégica de presentarse de una u otra forma. El mismo individuo, en la búsqueda de evitar la posibilidad de ser discriminado en contra en tanto "cholo" puede intentar aparecer en otro nivel como procedente de la capital, como hombre, como empresario, etc. Un "chino" -esto es, un peruano de origen asiático- o un judío pueden o no ser considerados auténticamente peruanos dependiendo de la forma en que negocien su posición en los intercambios argumentativos públicos.

Una adicional característica de la esfera pública en el Perú es que la diversidad de públicos entraña también diversidad en las prácticas comunicativas. Cada público tiene sus rituales y recursos expresivos. Da Matta (1978) plantea para la sociedad brasileña una imagen que es muy sugerente para entender la vida pública peruana: la asociación de las instituciones del poder político con el desfile, la vida religiosa con la procesión y el mundo popular con el carnaval. En el Perú es posible, en efecto, descubrir sin mayor esfuerzo que los públicos oficiales se hallan constantemente envueltos en rituales que reproducen y amplifican su propia majestad y jerarquía, en tanto que los públicos liminales hacen constante uso de estrategias expresivas que utilizan elementos de desorden y agitación para dramatizar sus demandas.

Las manifestaciones populares son además espacio privilegiado para la oralidad, lo que es importante en una sociedad donde la pre- y la post-modernidad convergen para precarizar el mundo de las letras: una, en tanto que el Perú arrastra a finales del siglo XX altas tasas de analfabetismo y un débil sistema de instrucción pública, y la otra en tanto los medios de comunicación electrónica visual y auditiva han hecho común formas de argumentación que reducen el poder de la palabra escrita.

Las movilizaciones en respaldo de la asediada "Frecuencia Latina" o las que ocurrieron casi paralelamente para rechazar la impugnación de los miembros del Tribuna Constitucional que habían declarado inaplicable a Fujimori la reelección son buenos ejemplos del poder de la oralidad, tanto como forma de comunicación como en tanto estrategia organizativa. Las movilizaciones se convocaban de manera informal, de boca en boca y multiplicaban sus efectos debido a la alianza de intereses entre los que protestaban y un medio de comunicación electrónico de alcance nacional, que difundía protestas que ocurrían en todo el país diariamente.

La efectividad y masividad de las protestas de 1997 hacen pensar en la existencia de circuitos orales informales de circulación de mensajes e ideas que posiblemente utilizan redes familiares, regionales o comerciales previamente existentes. Ciertamente estos circuitos han sido activados en otras ocasiones: notablemente en los casos de las elecciones presidenciales de 1990, en las que ninguna encuesta pudo anticipar el rápido crecimiento de la candidatura de un desconocido, que era solamente conocido como "el chinito" y que llegó a obtener votaciones significativas incluso en lugares en los que nunca hizo campaña.

\section{Una redefinición racializada de la representación política}

Hasta ahora hemos intentado responder al porqué del discurso sobre las clasificaciones raciales emerge de una forma tan violenta y polarizadora en el terreno del debate público, mostrando el carácter problemático de la noción de "lo peruano" y su debilidad para ocultar la urgente necesidad de una tematización pública de nuestra pluralidad. Sin embargo, como vimos en la polémica de las nacionalidades de Ivcher y Fujimori, es también necesario explicar cuál es la especificidad política de este problema: si el discurso reprimido sobre nuestro racismo buscaba emerger por cualquier válvula de escape, es necesario saber por qué es que la discusión sobre la democracia fue esa válvula de escape.

El motivo inmediato de la discusión en el caso "Frecuencia Latina" era la nacionalidad como autorización legal para ejercer unos determinados derechos: se necesita ser ciudadano peruano para poseer un canal de televisión, se necesita ser un ciudadano nacido en el Perú para ser presidente. Pero ambos son aspectos de un problema mayor, que es el de los criterios de inclusión en esa identidad ciudadana que permite participar políticamente.

Si es importante saber quién es peruano, esto ocurre porque el discurso político nacional ha desplazado la noción de representación política de una dimensión formal legal hacia una dimensión esencialista y simbólica. Sólo aquéllos reconocidos como peruanos pueden participar en la política del país; específicamente, si se espera ejercer alguna función en un sistema político donde el liderazgo se selecciona por el voto, es preciso ser reconocido como "representativo" de un determinado sector social constituído en electorado.

Pero los contenidos de ese "ser representativo" han variado en las últimas décadas. La noción de que el Perú es una democracia, esto es, una comunidad política basada en un sistema de gobierno representativo debe forzosamente tener contenidos distintos según lo que se entienda por la función de representación política.

La representación puede entenderse de manera no problemática, formalista (Pitkin, 1967. Cap. 3), como la función política por la cual un agente que ha recibido una autorización política por la via del sufragio, actúa con consecuencias legales para la comunidad. Una crítica al sistema basado en tal mecanismo puede dirigirse hacia la incapacidad del agente de satisfacer las expectativas de quienes le autorizaron con su voto, es decir, puede cuestionar la eficacia del agente y tildarlo de "mal representante", pero tal crítica no puede lógicamente cuestionar la esencia de la agencia en cuestión ni la "representatividad" del agente. En otras palabras, puede decirse " $\mathrm{X}$ es un mal representante del pueblo peruano", pero no puede decirse " $\mathrm{X}$ no es un auténtico representante del pueblo peruano". En el momento en que esta segunda crítica aparece, estamos frente a una concepción distinta de la representación política. 
El fujimorismo como régimen no se diferencia demasiado de otras experiencias de autoritarismo en el sentido que intenta justificar su destrucción de la democracia en el nombre de una nueva, superior y más auténtica democracia. Es necesario, por lo tanto, examinar los argumentos que utilizó contra el régimen constitucional de 1980-1992 y la propuesta de nueva democracia que inauguró a partir del autogolpe de 1992.

El pronunciamiento del 5 de abril de 1992 trataba de justificar la disolución del Congreso y la suspensión de la Constitución dejando claro que éste conjunto de medidas no era “...la negación de la democracia real, sino, por el contrario, (...) el punto de búsqueda de una auténtica transformación que asegure una democracia legítima y efectiva..." (Fujimori, 1994 p. 156): la legitimidad y la efectividad eran las dos puntas de lanza del discurso crítico del nuevo régimen contra la democracia de los años ochenta y en particular contra el parlamento, la instancia que había encabezado la resistencia a las tendencias autoritarias expresadas por Fujimori en los dos primeros años de su presidencia.

En un primer nivel se sostenía que la democracia representativa no era legítima, esto es, no era auténticamente una democracia porque traicionaba las expectativas de inclusión y participación de la ciudadanía. En lugar de tomar decisiones a partir de una deliberación pública, el parlamento era en realidad una careta que ocultaba las negociaciones secretas entre poderosos intereses privados. Los "políticos tradicionales" de los diversos partidos políticos habían dejado de representar al pueblo que los eligió porque optaban por representar a determinados grupos privilegiados. En este contexto, podía decirse que la democracia era solamente formal, no real: "La actual formalidad democrática es engañosa, falsa; sus instituciones sirven a menudo los intereses de todos los grupos privilegiados" (Fujimori, 1994, 154). Este argumento presentaba, por cierto, una implícita promesa de más -no menos- participación, lo que se llevó a cabo con el uso sistemático de mecanismos plebiscitarios y con la inclusión de nuevas formas de iniciativa ciudadana en la nueva Constitución que se aprobaría en 1993 (lo que, por cierto, no quiere decir que el gobierno haya permitido jamás que estas nuevas instituciones se lleven a cabo de forma autónoma).

En un segundo nivel, se sostenía que la democracia representativa no era un mecanismo eficiente de gobierno. Por un lado, un sistema basado en una instancia como el parlamento dedicada a la discusión corría el riesgo de no llegar jamás a decisiones. Los políticos de partido fueron satanizados como charlatanes incansables incapaces de llevar a cabo ninguna decisión práctica. Este es un viejo argumento en la política peruana, el general Odría (1948-1956) que llevó a cabo una dictadura populista de derecha muy semejante en su programa económico al fujimorismo acuñó la frase “Hechos, no palabras!” para publicitar sus obras y atacar a los políticos civiles. Por otro lado, la ineficacia de la democracia parlamentaria tenía que ver con la esencia misma de un modelo que propende a la formación de consensos y alianzas: los políticos forman alianzas redistributivas para favorecer a los grupos de interés que les apoyan, con lo que niegan la supuesta eficiencia natural del mercado (Tantaleán, 1996).

Ambas críticas le permitieron al fujimorismo contar con una formidable tenaza ideológica: por un lado, la crítica de la ilegitimidad del viejo régimen le permitía presentarse como un experimento de democracia radical; por otro lado, la crítica a la ineficacia de los políticos tradicionales le permitía justificar el neoliberalismo autoritario.

Tan exitosa fue la destrucción de las nociones formales legales de representación política que estas tuvieron que ser reconstruídas sobre una nueva base. No era suficiente para el nuevo personal político el proyectar una imagen de representantes legítimos y eficaces: había que refundar la representación sobre una nueva base, y esta fue dada por la utilización instrumental de la discusión sobre la diversidad racial.

En la campaña presidencial de 1990, Fujimori se había presentado explícitamente como el candidato "de los chinitos y los cholitos" contra el candidato de "los blanquitos" y había acuñado el lema "Un presidente como tú” como respuesta a los ataques racistas que sufriera desde el campo vargasllosista. Este "ser como tú" se constituiría con el tiempo en la base de una reformulación de la representación política como implícita representatividad racial: el nuevo personal político debía ser - al menos debía presentarse como- más cholo, más provinciano, en suma, más parecido a las mayorías nacionales, que los políticos de partido. De una noción formalista de representación política se pasaba a una representación descriptiva (Pitkin, 1967. Cap. 4) en la que el cuerpo político debía reflejar las características típicas del cuerpo de la nación.

Sin embargo, a diferencia del argumento por una radicalización de la democracia, que tuvo como efecto la constitucionalización de formas participativas como el referendum y la revocatoria de autoridades, este argumento no tuvo consecuencias de diseño constitucional. Hubiera sido esperable, por ejemplo, que se reformase el sistema electoral para formar distritos electorales que permitiesen una mejor representación de minorías étnicas, y sectores populares. Lo que sucedió fue todo lo contrario: el viejo parlamento bicameral elegido en veinticuatro distritos electorales nacionales se convirtió en un parlamento unicameral elegido en un distrito electoral único, para impedir -de acuerdo al razonamiento de los constituyentes- el caciquismo de líderes regionales y garantizar el mandato constitucional que los representantes se deben a la nación en su conjunto. La racialización implícita del concepto de representación política no fue consecuente porque fue estrictamente instrumental y no respondía a ningún principio: dividir al país en blancos y cholos servía para destruir a la vieja clase política, pero llevar adelante un reconocimiento constitucional práctico de la diversidad podía favorecer a los "caciques regionales" en perjuicio del gran cacique nacional.

La inestable resolución de este impasse ideológico implicó enfatizar las funciones representativas de la figura presidencial. Si un concepto formalista de representación había sido declarado obsoleto y un concepto descriptivo había sido descartado antes de nacer, era necesario enfati- 
zar un modelo distinto: la representación como simbolización (Pitkin, 1967. Cap. 5). El presidente, de acuerdo al texto constitucional "personifica a la nación" (Constitución Política del Perú, art. 110), lo que evoca su función como representante a un nivel superior al de simple agente de ciertos intereses o al de personaje "típico" de un cierto cuerpo social: la representación es en este caso simbolización de algo inaprehensible -la nación- a través de la persona y la majestad del soberano.

Habermas (1962) consideraba la "publicidad representativa”, esto es, la dramatización del poder en la persona del Rey como una forma primitiva de la formación de la esfera pública: la idea de la figura presidencial como personificación de la nación es un remanente moderno de aquélla institución primitiva. Lo relevante para nuestro caso es que esta forma se presta para el estilo populista del fujimorismo, que ha llevado a cabo una extraordinaria concentración de poderes en la presidencia y que la ha convertido en el centro de un permanente activismo mediático. Fujimori no publicita los momentos en que delibera y planifica, sino los momentos en los que actúa: la toma de decisiones es un arcano, la efectivizacion de esas decisiones, un show televisivo.

\section{CONCLUSIONES}

El Perú vive el problema de haber sometido a una corrosiva crítica una noción esencial para el funcionamiento del sistema democrático -la representación política- sin haber explicitado los supuestos que subyacen a tal crítica y que nos trasladan a la necesidad de un debate sobre la diversidad étnica y racial del país.

La crítica a la representación y la preocupación por la auténtica peruanidad de los actores políticos están animadas por la fuerza de un discurso sumergido que no emerge en una esfera pública fracturada y deficitaria en su capacidad de inclusión. Pero esta fuerza no se ha utilizado, ni para llevar a cabo una sincera autocrítica del racismo cotidiano y los esencialismos nacionalistas, ni para imaginar un rediseño de las instituciones democráticas a fin de garantizar una mayor inclusión.

La fuerza de este discurso sumergido ha sido, por el contrario, instrumentalizada desde el poder para satanizar a los rivales políticos del fujimorismo. Sin embargo, una vez ejercido, el discurso ambiguamente racializante del régimen se convierte en una caja de Pandora que puede volverse contra aquéllos que la han abierto, como lo muestra el hecho que la oposición empiece a utilizar los mismos argumentos en contra de Fujimori.

\section{REFERENCIAS BIBLIOGRÁFICAS}

Callirgos, Juan Carlos (1993) El racismo: la cuestión del otro (y de uno). Lima: Desco.

Constitución Política del Perú 1993 (1995) Sumillada por Landa, César y Velasco, Ana. Lima: Universidad Católica.
DA MATTA, Roberto (1978) Carnavais, malandros e herois. Para uma sociologia do dilema brasileiro. Rio: Zahar.

De Soto, Hernando (1993) "Esperando el segundo tiempo " Entrevista en Cuestión de Estado, 3: 23-28.

Degregori, Carlos Iván (1991) "El aprendiz de brujo y el curandero chino. Etnicidad, modernidad y ciudadanía” en Degregori, Carlos Iván y Grompone, Romeo Demonios y redentores en el nuevo Perú. Una tragedia a dos vueltas. Lima: IEP.

Delgado Diaz del Olmo, César (1992) "Psicosis y mestizaje" en Márgenes, 9: 186-206

Franco, Carlos (1991) "Exploraciones en "Otra Modernidad": de la migración a la plebe urbana” en Urbano, Henrique (ed.) Modernidad en los Andes Cusco: Bartolomé de las Casas.

Franco, Carlos (1993) "Pensar en otra democracia" en Cuestión de Estado, 3: 10-16.

FujIMORI, Alberto "Manifiesto a la nación" (1994), en Arias Quincot, César La modernización autoritaria. La nueva institucionalidad surgida a partir de 1990. Lima: Fundación Ebert

Grompone, Romeo (1995) "Nuevos tiempos, nueva política" en Grompone, Romeo y Mejía, Carlos, Nuevos tiempos, nueva política. El fin de un ciclo partidario. Lima: IEP.

HeRnÁNDEZ, Max (1993) Memoria del bien perdido. Conflicto, identidad y nostalgia en el Inca Garcilaso de la Vega. Lima: IEP.

Fraser, Nancy (1992) "Rethinking the public sphere: A Contribution to the Critique of Actually Existing Democracy" en Calhoun, Craig (ed.) Habermas and the public sphere. Cambridge: MIT.

LÓPEZ, Sinesio (1997) Ciudadanos reales e imaginarios. Concepciones, desarrollo y mapas de la ciudadanía en el Perú. Lima: IDS.

LynCH, Nicolás (1992) Para cambiar el Estado. La reforma del Congreso Nacional Lima: IDS

Pease, Henry (1993) "Desde dentro y desde fuera del CCD" en Cuestión de Estado, 2: 24-27.

PITKIN, Hannah (1967) The Concept of Representation. Berkeley: University of California.

Plot, Martín (1998) "On Political Kitsch, Events and Public Time in Contemporary Argentina" ponencia presentada en el XXI Congreso de la Latin American Studies Association. Chicago, Setiembre de 1998.

ROCHABRUN, Guillermo (1994) “¿Crisis de representatividad? ¿O crisis de intermediación?” en Cuestión de Estado, 7: 10-15.

SALMON, Jorge (1993) Entre la vanidad y el poder. Memoria y testimonio. Lima: Apoyo.

SchmitT, Carl (1995) La defensa de la constitución. Estudio acerca de las diversas especies y posibilidades de salvaguarda de la Constitución. Madrid: Tecnos

TANTALEAn, Javier (1996) “¿Liquidación de los partidos? Ideología neoliberal y ciclos políticos en la historia” en Socialismo y Participación, 73: 81-95.

Toledo, Alejandro (1997). Entrevista personal con el autor. Lima. 
VARGAS LlOSA, Mario (1994)The Fish in the Water. A Memoir. New York: Farrar Straus Giroux.
Zuzunaga, Carlos (1992) Vargas Llosa: el arte de perder una elección. Lima: Peisa.

\section{RESUMEN}

La escena política peruana, a partir de la ascensión del régimen fujimorista, se ve dominada por argumentos que ligan la discusión sobre democracia y autoritarismo con el tema de la identidad nacional. El artículo sostiene que esta ligazón es posible por la convergencia de dos procesos político-culturales: 1) la crisis de un discurso "criollo" sobre la raza y la etnicidad que ha fracasado en el intento de postular una imagen de nación homogéneamente mestiza, y 2) el agotamiento de los significados liberales del concepto de representación política, que han sido desplazados por nociones de representatividad descriptiva de identidades étnicas.

Palabras clave: Nación, etnicidad, democracia, representación política, esfera pública.

\section{ABSTRACT}

After the emergence of the Fujimori regime, the Peruvian political arena has been dominated by arguments linking the discussion on democracy and authoritarianism with the topic of national identity. The article maintains that this linkage is made possible by the convergence of two political-cultural processes: 1) the crisis of a creole discourse on race y ethnicity that has failed in the attempt to build an image of a homegenous mestizo nation, and 2) the exhaustion of the liberal meanings of the concept of political representation, that have been replaced by notions of descriptive representativeness of ethnic identities.

Key words: Nation, ethnicity, democracy, political representation, public sphere.

\section{AMAUTA}

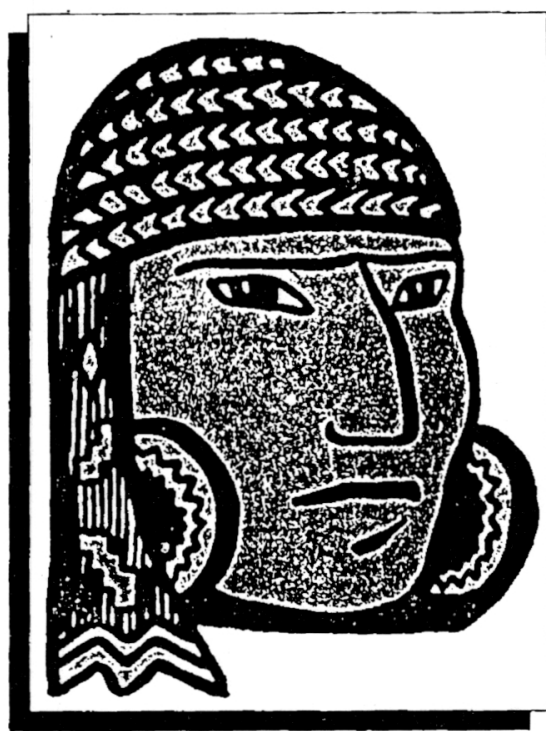

Documentos Inaugurales 


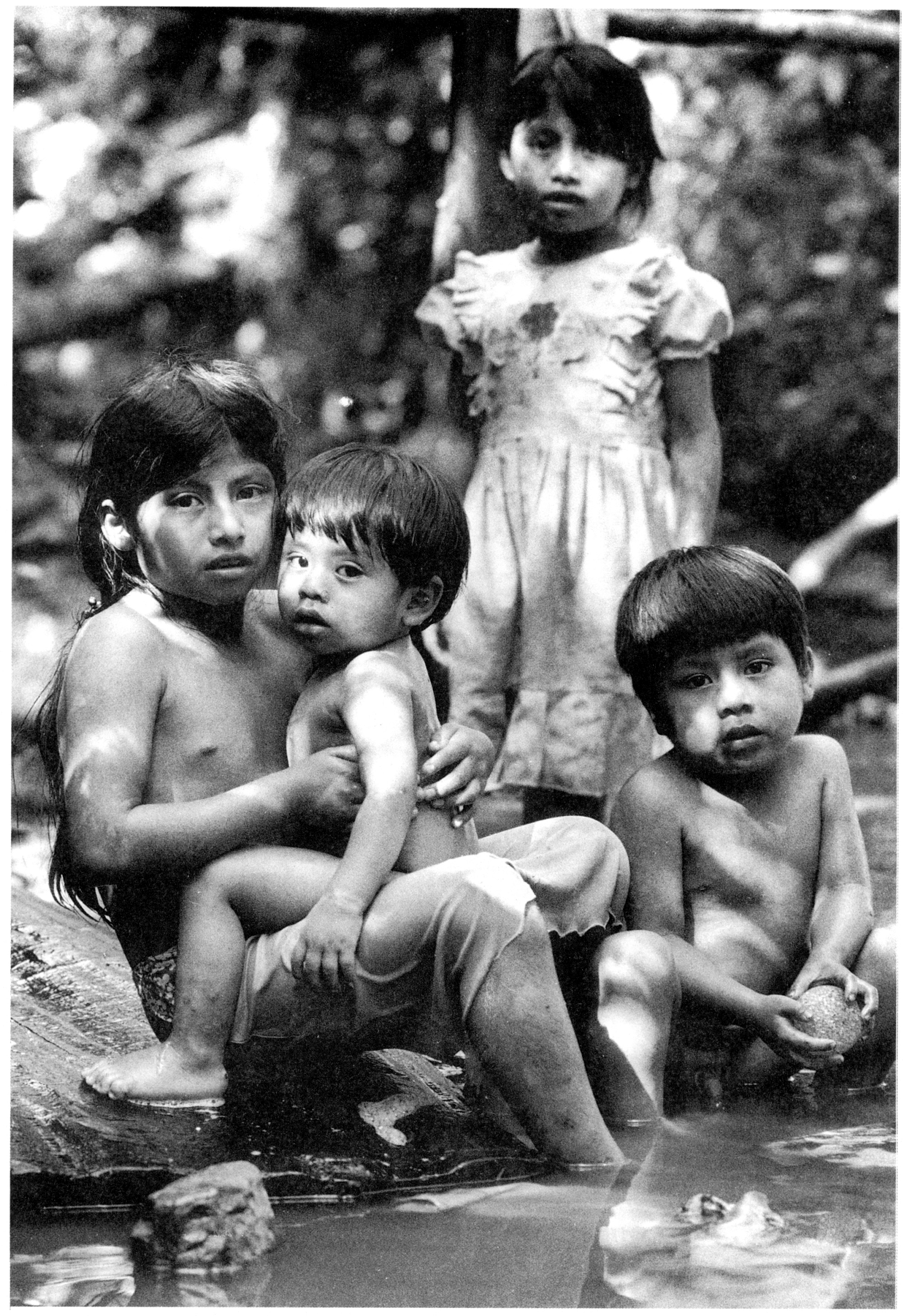

